\title{
Catharanthus roseus Combined with Ursolic Acid Attenuates Streptozotocin-Induced Diabetes through Insulin Secretion and Glycogen Storage
}

\author{
Huda Mohammed Alkreathy ${ }^{1}{ }^{1}$ and Aftab Ahmad ${ }^{2}$ \\ ${ }^{1}$ Department of Pharmacology, Faculty of Medicine, King Abdulaziz University, Jeddah, Saudi Arabia \\ ${ }^{2}$ Health Information Technology Department, Faculty of Applied Studies, King Abdulaziz University, Jeddah -21589, Saudi Arabia
}

Correspondence should be addressed to Aftab Ahmad; aftab786sa@hotmail.com

Received 21 November 2019; Revised 7 January 2020; Accepted 29 January 2020; Published 19 February 2020

Academic Editor: Rajeshwary Ghosh

Copyright (c) 2020 Huda Mohammed Alkreathy and Aftab Ahmad. This is an open access article distributed under the Creative Commons Attribution License, which permits unrestricted use, distribution, and reproduction in any medium, provided the original work is properly cited.

\begin{abstract}
Catharanthus roseus (C. roseus) and ursolic acid (UA) are ayurvedic medicines with multiple pharmacological activities including antidiabetic activity, but till date, no study is available on their combination. This study documented the antidiabetic efficacy of the combination of $C$. roseus and UA in rats. Rats were divided into six groups. All groups were given a single dose of Streptozotocin (STZ) at a dose of $50 \mathrm{mg} / \mathrm{kg}$ by intraperitoneal route for induction of diabetes, except the normal control group. Group 1 was treated as a normal control (NC) group and fed with saline water, Group 2 as a Diabetes Control group, Group 3 as a STZ+C. roseus ethanolic extract (CREE) group at $50 \mathrm{mg} / \mathrm{kg}$ p.o., Group 4 as a STZ+UA group orally at $50 \mathrm{mg} / \mathrm{kg}$, Group 5 as a STZ+CREE $(25 \mathrm{mg} / \mathrm{kg}$ p.o. $)+\mathrm{UA}(25 \mathrm{mg} / \mathrm{kg}$ p.o.) group, and Group 6 as a STZ+Glimepiride $(0.1 \mathrm{mg} / \mathrm{kg})$ group. Diabetes was confirmed after 72 hours by estimation of blood glucose level, and then treatment was given for the next 28 days. During the course of treatment, plasma insulin and blood glucose were measured regularly at the interval of 7 days. At the end of the protocol, blood was collected and animals were sacrificed. The glucose level, insulin level, liver glycogen storage level, and antioxidant enzymes (LPO, CAT, SOD, GPx, GST) were measured. The blood glucose level in Group 5 significantly $(P<0.001)$ reduced to $98.35 \pm$ $2.45 \mathrm{mg} / \mathrm{dl}$ in comparison with that in Group $2(321.75 \pm 5.46 \mathrm{mg} / \mathrm{dl})$. The level of plasma insulin in Group 5 increased $(13.65 \pm 0.10 \mu \mathrm{U} / \mathrm{ml})$ significantly $(P<0.01)$ as compared with that in Group $2(05.93 \pm 0.31 \mu \mathrm{U} / \mathrm{ml})$. In Group 5, the level of glycogen in liver was significantly $(P<0.01)$ increased as compared with that in Group 2 rats. The level of antioxidant enzymes in Group 5 restored toward normal values significantly $(P<0.01 ; P<0.001)$ as compared with that in Group 2 animals. These findings suggest that low-dose combination of CREE and UA is effective in the treatment of diabetes.
\end{abstract}

\section{Introduction}

Diabetes is a metabolic disease which induced either due to the inability of pancreas to secrete sufficient insulin in body or when body is unable to use insulin effectively for the regulation of blood sugar. In both conditions, a large amount of sugar remains in blood. The increased sugar of blood is an identifying parameter for diabetes and this increased level for long time creates severe injury to multiple organ systems of the body. In year $2014,8.5 \%$ of the adults suffered from diabetes. In year 2016, 1.6 million casualties were linked with diabetes. According to the 2011 Diabetes National Fact Sheet, around $8.3 \%$ people in the United States suffer from diabetes. Around $27 \%$ of the people already suffering from diabetes do not have knowledge that they have diabetes. The number of patient of diabetes increased more than $400 \%$ from year 1980 to 2014. Prevalence of diabetes increased mainly in undeveloped and developing countries, where income of the peoples is low. The diabetes is a main causative factor of kidney failure, blindness, stroke, heart attacks, and the amputation of limb. In year 2016, around 1.60 million casualties were associated with diabetes. Further, 2.20 million casualties were associated with the increased sugar level of blood in the year 2012. World Health Organization estimated 
that diabetes was the $7^{\text {th }}$ major reason of casualty in the year 2016. This is estimated that approximately 425 million adults were suffering from diabetes in the year 2017 around the globe, as per the reports of the International Diabetes Federation. This is further postulated that the total prevalence of diabetic patients is expected to increase up to 629 million by the year 2045 [1]. Lifestyle management is an essential feature of diabetes care, which includes physical work, exercise, healthy food, psychosocial care, maintaining normal weight of body, and avoiding the use of tobacco can delay or prevent the induction of type 2 diabetes mellitus [2].

Catharanthus roseus (C. roseus), popular with periwinkle synonym, is a flowering plant that belongs to the Apocynaceae family. In the ayurvedic system of medicine, its root and bark extract are used traditionally for the treatment of various kinds of diseases. In the Chinese alternative medicine system, decoction was utilized for the treatment of various disorders, which includes Hodgkin lymphoma, malaria, as well as diabetes. Previously, various alkaloids were extracted from this plant, of which vincristine and vinblastine got significant importance and utilized for the management of Hodgkin lymphoma and blood cancer [3].

Ursolic acid (UA) is a very unique triterpenoid molecule present in medicinal plant, kingdom plantae, and utilized as an important part of the human food. Various recently studies reported the wide spectrum pharmacological potentials of UA. It exhibits a variety of effects including antimicrobial, anti-arthritic, and anticancer effects against variety of cancers $[4,5]$. Numerous bioactivities of UA have been reported, but till date no clinical work available which demonstrates beneficial effects to human health care. In pre-clinical study, UA decreases the growth of many cancerous cells by inhibition of STAT-3 pathway in cell $[6,7]$ and also reduce cancerous cell proliferation by induction of apoptotic pathway $[8,9]$. UA also inhibits JNK-expression and activation of IL-2 of JURKAT leukemia T-Cells which leads to the proliferation reduction and activation of T-Cell [10]. As per previous work, UA is a weak inhibitor of aromatase enzyme [11], and it increases the brown fat and muscle amount and decreases the obesity of white fat and related conditions when present in fed of mice. UA under physiological concentrations also induces erythrocyte apoptosis (programmed cellular death of red blood cells). It also reduces the atrophy of muscle and enhances the growth of muscles in mice, which also exhibits significant cardio-protection activity [12]. In animals, UA shows neuronal regeneration property after injury of nerve. UA is effective in the treatment of cognitive impairment in animals. UA is also used in the improvement of cognitive disorders by blockage of stress of endoplasm reticulum and nuclear factor- $\kappa \mathrm{B} / \mathrm{I} \kappa \mathrm{B}$ kinase $\beta$-mediated pro-inflammatory path in animals. UA improves lipopolysaccharide-induced cognition disorder in brain of mice by suppression of $\mathrm{p} 38 / \mathrm{NF}-\kappa \mathrm{B}$-inflammatory path. UA improves cognition impairment and modulates oxidative stress damage in mice brain induced by $\mathrm{D}$ galactose. UA improves regeneration of liver of mice after partial removal of part of liver [13]. UA modulates cellular immunity and improve function of pancreas $\beta$-cell in diabetic high fat diet animals. It increases mass of skeletal muscle, exercise capac- ity, and griping strength. UA attenuates aging metabolicphenotype by promotion of rejuvenation of skeletal muscle [9]. Recently, a pharmacological and docking studies on the influence of UA on adjuvant-induced arthritis reported that Ocimum sanctum L leaf extract (rich in UA) loaded nanostructured lipid carriers inhibited the COX-1, COX-2, IL-1, and TNF- $\alpha$; hence, ameliorate the arthritis in rats [14]. Moreover, the in vitro anti-proliferative activities of some novel synthetic quinoline derivatives of UA bearing hydrazide, oxadiazole, or thiadiazole moieties against three cancer cell lines (MDA-MB-231, HeLa, and SMMC-7721) have been recently reported [15]. C. roseus and UA are ayurvedic medicines which possess numerous pharmacological activities including antidiabetic activity, but till date, no study is available on their combination against STZ-induced diabetes in rats. Based on the published literature, it was thought worthwhile to evaluate the antidiabetic activity of $C$. roseus ethanolic extract (CREE) alone, UA alone, and combination of both C. roseus ethanolic extract (CREE) and UA. Further, it gives the idea about the beneficial effect of low-dose combination of $C$. roseus ethanolic extract (CREE) and UA. In view of the above background, the current study was designed for evaluation of antidiabetic potential of combination of $C$. roseus ethanolic extract (CREE) and UA in STZ-induced diabetic rats.

\section{Materials and Methods}

2.1. Chemicals and Drugs. Ursolic acid (UA) and Streptozotocin (STZ) were purchased from Sigma-Aldrich Chemical Company, St. Louis, (MO, USA). All other chemicals and solvents used in the study were of analytical grade and procured from an approved vendor. Standard pellet diet for animals was obtained from local supplier.

2.2. Ethanolic Extraction of Catharanthus roseus Leaves. Periwinkle leaves (C. roseus leaves) were collected from the gardens in the campus of King Abdulaziz University, Jeddah, and was authenticated by one of the botanist at King Abdulaziz University. Leaves were dried in shadow by avoiding direct sunlight for several days. After drying, the leaves were crushed into a coarsely powdered state and $0.1 \mathrm{~kg}$ of powdered drug was mixed in petroleum-ether and left aside for two days for removing all chloroplast, wax, and fats. After this, it was filtrated and then suspended in 95\% of $500 \mathrm{~mL}$ alcohol, and then extracted by using soxhlet apparatus for eighteen hours. After that, ethanol was evaporated by using rotary-evaporator at $40-44^{\circ} \mathrm{C}$ temperature. After significant evaporation, thick concentrated extract of ethanol was formed which was filtered by the use of a filter paper (coarse sieve). Then obtained filtrate was dried with reduced pressure and lastly it was lyophilized. This dried sample was used for experimentation purpose. The prepared C. roseus ethanolic extract (CREE) at a dose of $50 \mathrm{mg} / \mathrm{kg}$ of body weight was given orally, based on the previous published reports $[16,17]$.

2.3. Animals. Healthy male Wistar strain rats (5-6 months old) weighing 100-200 g were procured from the animal facility of King Fahad Medical Research Centre, King Abdulaziz 
University-Jeddah, Saudi Arabia. This research study was carried out by adopting the guidelines of the Institutional Animal Ethical Committee (IAEC) on the use and care of laboratory animals. The experimental rats were arbitrarily segregated into groups in different cages in standard setcontrolled conditions. Before the commencement of the dosing, the rats were acclimatized in the animal room for seven days by maintaining a temperature of $25^{\circ} \mathrm{C} \pm 2^{\circ} \mathrm{C}$; relative humidity of $30-70 \%$; and $12: 12 \mathrm{~h}$ light/dark cycle. The rats were given free access to standard quality pallet diet and tap water ad libitum.

2.4. Initiation of Diabetes in Rats. STZ was be used for the induction of diabetes in rats. The animals were in fasting for sixteen hours before the diabetes induction. STZ was freshly prepared in the $0.05 \mathrm{M}$ citrate buffer with value $\mathrm{pH} 4.5$. A single dose of STZ (50 mg per kg, body weight) was administered to the rats by intraperitoneal injection to induce the diabetes [18]. The diabetes induction was accessed by polyuria, polydipsia, and by the measurement of concentrations of blood glucose after 72 hours of administration of Streptozotocin and then treatment was given for next 28 days.

2.5. Experimental Design. Animals were acclimatized and allocated randomly in the six groups $(n=6)$ and rats were treated as per the following schedule for the period of 28 days. The body weights of the experimental rats were recorded using an electronic weighing balance before starting the treatments and at the termination of the protocol.

Group 1 (normal control group): the rats were fed with normal saline $(0.9 \%)$ and served as normal control (NC).

Group 2 (Diabetes Control group): diabetes was induced by a single intraperitoneal injection of STZ $(50 \mathrm{mg} / \mathrm{kg}$, body weight).

Group 3 (CREE treated group): STZ+C. roseus ethanolic extract (CREE) at a dose of $50 \mathrm{mg} / \mathrm{kg}$ of body weight by oral route.

Group 4 (UA treated group): STZ+UA (50 mg per kg, body weight) by oral route.

Group 5 (CREE+UA treated group): STZ+CREE (25 mg per $\mathrm{kg}$ of body weight, orally)+UA ( $25 \mathrm{mg}$ per $\mathrm{kg}$ of body weight, orally).

Group 6 (Glimepiride-treated group): STZ+Standard Glimepiride $(0.1 \mathrm{mg} / \mathrm{kg}$, orally).

2.6. Estimation of Biochemical Parameters. At the end of protocol, the whole blood was withdrawn from the retroorbital cavity of the animal in the light anesthesia. On the termination, blood was left aside to stand for thirty minutes at room temperature without anticoagulant. Then it was subjected to centrifuge for ten minutes at $2500 \mathrm{rpm}$ to separate the serum at $4^{\circ} \mathrm{C}$. The obtained serum was then held back at lower temperature $\left(2-3^{\circ} \mathrm{C}\right)$ for further measurement of different biochemical study. Serum insulin and glucose levels were determined by enzymatic methods with the help of an automated analyzer (Dimension Vista ${ }^{\circledR}$ system, Siemens, Germany) using standard biochemical kits [19].

2.7. Estimation of Oxidative Stress Markers. The animals were euthanized by chloroform overdose, and their liver was iso- lated and washed in normal saline solution $(0.9 \% \mathrm{NaCl}$ solution in distilled water). The liver tissues were then perfused with $50 \mathrm{mmol} / \mathrm{L}$ sodium phosphate buffer solution ( $\mathrm{pH} 7.4$ ), which also contained EDTA $(0.1 \mathrm{mmol} / \mathrm{L})$, to drain the blood clots and cells. The part of the liver was homogenized in phosphate buffer $(0.1 \mathrm{M} ; \mathrm{pH} 7.4)$ and carefully centrifuged at $10,000 \mathrm{rpm}, 15$ minutes at $4^{\circ} \mathrm{C}$. The clear supernatant was then used to assess antioxidant enzymes such as Glutathione peroxidase (GPx), Glutathione-S-transferase (GST), superoxide dismutase (SOD), catalase (CAT), and lipid peroxidation (LPO) by the method of Shivavedi et al., 2017 [20].

2.8. Statistical Analysis. All the data was analyzed using the SPSS (Statistical Package for the Social Sciences) version 20.0 software (SPSS Inc., Chicago, IL, USA). The data was expressed as Mean \pm SEM. The significance among different groups was determined by using one-way analysis of variance (ANOVA) test. $P$ value of ${ }^{*} P<.05,{ }^{* *} P<.01$, and ${ }^{* * *} P<.001$ were considered to be statistically significant, when compared with the control group.

\section{Results}

3.1. Effect on Body Weight. The effect of the treatment on body weight in STZ-induced diabetic rats is represented by the graph in Figure 1. It can be clearly seen that the body weight of Group 2 at the end of the study was significantly decreased $(P<0.01)$ by $32 \%(136.86 \mathrm{~g})$, whereas Group 1 had almost no change. On the other hand, between the groups receiving single drug treatment, Group 4 (179.64 g) showed better recuperation of body weight than Group 3 $(174.56 \mathrm{~g})$. Contrastingly, Group 5 had the best result $(201.76 \mathrm{~g})$ as it was administered the combinational therapy and the results were strikingly similar to that of the standard drug treatment Group 6. The body weight analysis outlines that the combinational treatment has promising results and hence potential antidiabetic activity may be evident.

3.2. Blood Glucose Level. STZ-induced diabetic rats exhibited an increase in the level of blood glucose $(P<0.05)$; the glucose level peaked more than 3 times than that of Group 1 rats. Over the course of 4 weeks, on the treatment with single drugs, it was found that Group 3 and Group 4 treated with CREE and UA, respectively, had almost similar results where the blood glucose level lessened nearing the normal (Table 1). The decrease in the treatment group was significant as compared with Group $1(P<0.05$ in all cases) and Group $2(P<0.05$ in all cases). The combination treatment of rats in Group 5 with CREE and UA showed striking results as the blood glucose level $(98.35 \pm 2.45 \mathrm{mg} / \mathrm{dl})$ in this group was below the normal rats $(101.64 \pm 2.82 \mathrm{mg} / \mathrm{dl})$ at the end of the study. The result of Group 6 was considered the standard and hence it showed the best results in lowering the blood glucose level in rats (Table 1).

3.3. Plasma Insulin Level. Post STZ administration, on Day 0, the level of plasma insulin was found to be decreased significantly $(P<0.05)$ in the rats of all groups (below $7.00 \mu \mathrm{U} / \mathrm{ml}$ ) except Group $1(15.65 \pm 0.24 \mu \mathrm{U} / \mathrm{ml})$ as evident from Table 2. At the end of the study, it was observed that the 


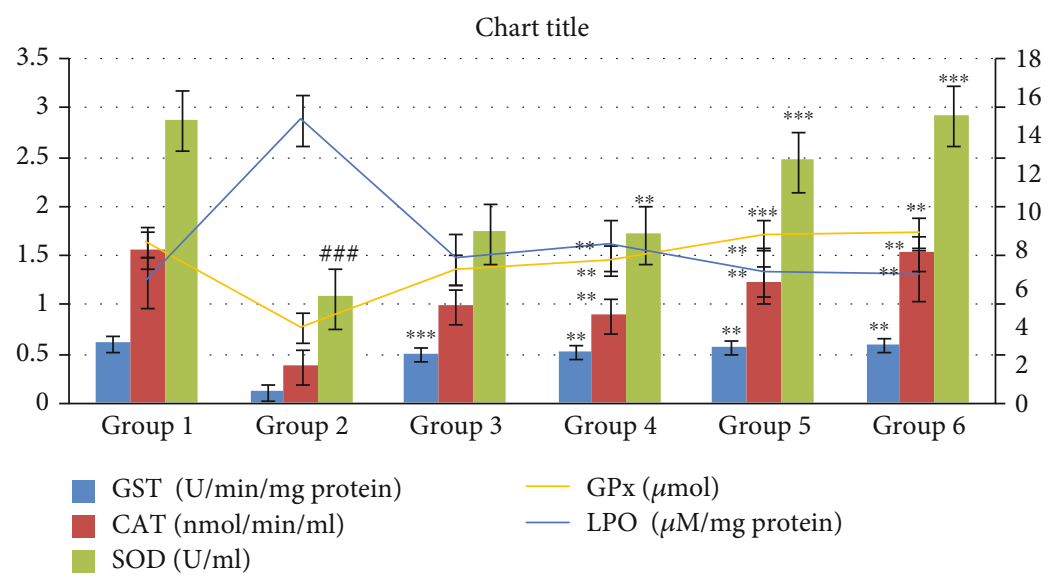

Figure 1: Effect Catharanthus roseus and ursolic acid and combination on body weight. ${ }^{* *} P<0.01$ is considered significant, ${ }^{* * *} P<0.001$ is considered highly significant. Group 2 compared with Group 1, and comparison is considered significant. ${ }^{\# \#} P<0.01$ is considered very significant; ${ }^{\# \# P}<0.001$ is considered highly significant.

TABLe 1: Effect Catharanthus roseus and ursolic acid and combination on blood glucose level (mg/dl).

\begin{tabular}{|c|c|c|c|c|c|}
\hline \multirow[t]{2}{*}{ Groups } & \multicolumn{5}{|c|}{ Days } \\
\hline & 0 day & $7^{\text {th }}$ day & $14^{\text {th }}$ day & $21^{\text {st }}$ day & $28^{\text {th }}$ day \\
\hline Group 1 & $098.65 \pm 2.17$ & $099.98 \pm 2.46$ & $102.86 \pm 2.46$ & $99.84 \pm 1.84$ & $101.64 \pm 2.82$ \\
\hline Group 2 & $285.47 \pm 4.68$ & $293.45 \pm 4.57^{\# \#}$ & $302.45 \pm 3.67^{\# \# \#}$ & $315.86 \pm 6.33^{\# \# \#}$ & $321.75 \pm 5.46^{\# \#}$ \\
\hline Group 3 & $275.26 \pm 3.96$ & $223.64 \pm 3.674^{*}$ & $158.35 \pm 2.57^{* *}$ & $110.85 \pm 246^{* *}$ & $109.46 \pm 5.46^{* *}$ \\
\hline Group 4 & $288.68 \pm 4.63$ & $215.85 \pm 3.75^{* * *}$ & $145.76 \pm 2.64^{* * *}$ & $105.45 \pm 3.75^{*}$ & $106.67 \pm 2.67^{* *}$ \\
\hline Group 5 & $283.46 \pm 5.86$ & $195.61 \pm 2.87^{* *}$ & $161.41 \pm 2.98^{* * *}$ & $098.56 \pm 1.82^{* *}$ & $098.35 \pm 2.45^{* * *}$ \\
\hline Group 6 & $271.96 \pm 4.46$ & $175.45 \pm 2.46^{* * *}$ & $120.24 \pm 1.86^{* *}$ & $080.34 \pm 1.56^{* *}$ & $077.45 \pm 1.46^{* *}$ \\
\hline
\end{tabular}

Values are expressed as Mean \pm SEM, $(N=6) .{ }^{\#}$ Groups as compared with Group $1 ;{ }^{*}$ groups as compared with Group $2 ;{ }^{*} P<0.05 ;{ }^{* *} P<0.01 ;{ }^{* * *} P<0.001$.

TABLE 2: Effect Catharanthus roseus and ursolic acid and combination on plasma insulin level ( $\mu \mathrm{U} / \mathrm{ml})$.

\begin{tabular}{|c|c|c|c|c|c|}
\hline \multirow[t]{2}{*}{ Groups } & \multicolumn{5}{|c|}{ Days } \\
\hline & 0 day & $7^{\text {th }}$ day & $14^{\text {th }}$ day & $21^{\text {st }}$ day & $28^{\text {th }}$ day \\
\hline Group 1 & $15.65 \pm 0.24$ & $15.91 \pm 0.11$ & $15.34 \pm 2.46$ & $15.98 \pm 0.12$ & $15.78 \pm 0.18$ \\
\hline Group 2 & $06.94 \pm 0.15$ & $06.85 \pm 4.57^{\# \#}$ & $06.43 \pm 0.17^{\#}$ & $06.05 \pm 0.16^{\# \#}$ & $05.93 \pm 0.31^{\# \#}$ \\
\hline Group 3 & $06.86 \pm 0.09$ & $08.74 \pm 3.674^{*}$ & $09.62 \pm 0.14^{* *}$ & $10.33 \pm 0.21^{* * *}$ & $10.41 \pm 0.20^{* *}$ \\
\hline Group 4 & $06.65 \pm 0.25$ & $08.56 \pm 3.75^{*}$ & $09.70 \pm 0.19^{* * *}$ & $11.11 \pm 0.12^{*}$ & $11.46 \pm 0.21^{* *}$ \\
\hline Group 5 & $06.76 \pm 0.16$ & $09.57 \pm 2.87^{* * *}$ & $10.46 \pm 2.98^{* * *}$ & $13.34 \pm 0.21^{* * *}$ & $13.65 \pm 0.10^{* *}$ \\
\hline Group 6 & $06.73 \pm 0.14$ & $10.11 \pm 0.14^{* *}$ & $12.56 \pm 0.16^{* *}$ & $16.01 \pm 0.09^{* *}$ & $15.97 \pm 0.18^{* * *}$ \\
\hline
\end{tabular}

Values are expressed as Mean \pm SEM, $(N=6) .{ }^{*}$ Groups as compared with Group 1; ${ }^{*}$ groups as compared with Group 2 ; ${ }^{*} P<0.05 ;{ }^{* *} P<0.01 ;{ }^{* * *} P<0.001$.

levels of plasma insulin were successfully restored in animals of group 3, 4, 5, and 6 significantly $(P<0.01$ in all cases). Group 5 which received the combined treatment of CREE and UA showed best restoration of the plasma insulin $(13.65 \pm 0.10 \mu \mathrm{U} / \mathrm{ml})$ in a significant manner.

3.4. Liver Glycogen Level. The effect of the treatments on liver glycogen storage level in STZ-induced diabetic rats is represented by the graph in Figure 2. Liver glycogen level was found to diminish in the rats administered with STZ, as in Group 2 it was found to decrease by more than $50 \%$ (34.34 mg/g tissue) as compared with Group $1(73.55 \mathrm{mg} / \mathrm{g}$ tissue) $(P<0.01)$. On the administration of the combination of CREE and UA, the liver glycogen level was significantly restored $(P<0.01)$ in Group $5(69.65 \mathrm{mg} / \mathrm{g}$ tissue) while the single treatment group receiving either CREE or UA showed noticeable elevation in the liver glycogen level $(P<0.01)$ in Group 3 and Group 4. The standard treatment Group 6 had almost normal level of liver glycogen.

3.5. Antioxidant Enzyme Level. The effect of CREE and UA on the activities of GST, SOD, CAT, GPx, and LPO in STZinduced diabetic rats is illustrated in Figure 3. In the rats treated with STZ, the activities of GST, CAT, GPx, and 


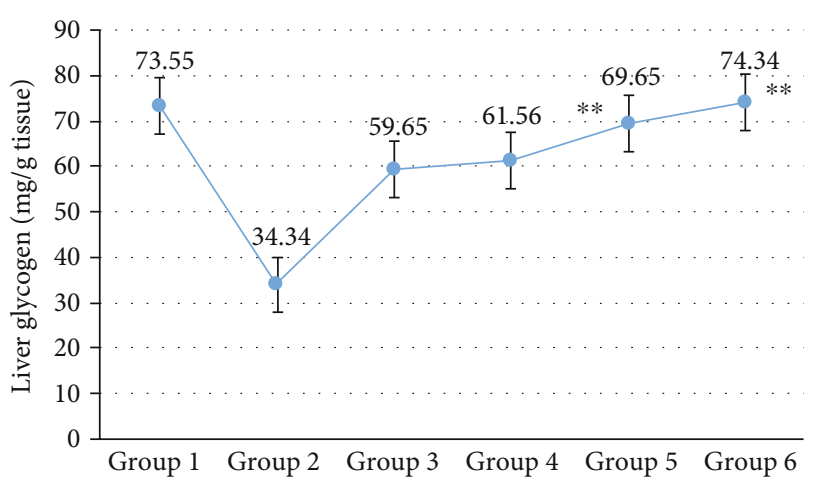

FIgURE 2: Effect Catharanthus roseus and ursolic acid and combination on liver glycogen level. ${ }^{* *} P<0.01$ is considered significant, ${ }^{* * *} P<0.001$ is considered highly significant. Group 2 compared with Group 1, and comparison is considered significant. ${ }^{\# \#} P<0.01$ is considered very significant; ${ }^{\# \# \# P} P<0.001$ is considered highly significant.

SOD were noticeably reduced $(P<0.01)$, whereas LPO was elevated significantly $(P<0.01)$ as compared with the disease control Group 2 rats (see Figure 3). In posttreatment with $\mathrm{CREE}$ and/or UA, the results were reversed, and remarkable restoration of the antioxidant enzyme was observed at the end of the study. In line with our study, plants possessing anti-hyperglycemic effects are used as potential sources for drug development worldwide. Medicinal plants containing flavonoids, alkaloids, terpenoids, glycosides, etc. are often considered to possess anti-hyperglycemic activity.

\section{Discussion}

Our study was aimed at investigating the antidiabetic activity of the combination of CREE and UA in STZ-induced diabetes in rats and also the evaluation of antioxidant capacity of these herbal extracts in order to establish scientific evidence for the use of CREE and UA in the treatment of diabetes. In our study, we deduced that anti-hyperglycemic action of the combination of CREE and UA was mediated by their antioxidant properties.

C. roseus contain several biological substances like flavonoids, terpenoids, tannins, phenolics, and glycosides [12, 21]. Type 2 diabetes mellitus is resultant of structural and functional changes in the beta cells of pancreas and is characterized by the reduced insulin secretion. The elevated blood glucose and other biochemical deviations in the serum level are caused due to the deficiency of insulin or due to insulin resistance in target organs (IDF). Out of the several models available for the induction of diabetes, we used STZ model as per the facility available in our research laboratory. STZ is a derivative of nitrosourea and has been used in mimicking diabetes in rodents. STZ enhances the production of free radicals and the free radical scavenger system is inhibited, which gives rise to oxidative stress and finally damages pancreatic beta cells. The selective destruction of beta cells leads to deficiency in the serum levels of insulin consequently leading to hypoglycemic condition $[22,23]$. In our study, we used a single dose of $50 \mathrm{mg} / \mathrm{kg}$ body weight of STZ for the induction of diabetic condition, following which the fasting blood glucose level elevated rapidly confirming the induction of diabetes in the rats under the study and it was also in confirmation of the previously reported studies [24-26].

Hyperglycemia is characterized by signs of polydipsia, polyuria, and loss of body weight. The reduction in body weight is associated with proteolysis in the skeletal muscle and the degradation of fats induced by non-availability of energy via breakdown of carbohydrates [27]. In this study, we found that the loss in body weight was noticeable in Group 2 rats, inferring a progressive proteolysis induced by the derangement of carbohydrate metabolism. The administration of combination of CREE and UA recuperated the body weight in Group 5 nearing to the normal and in congruence to the standard treatment Group 6. However, the restoration of body weight in the single treatment Group 3 and 4 was not that significant (Figure 1). The restoration of body weight showed that the treatment possibly worked in preventing muscle wasting by controlling the glycemic status.

The decreased level of insulin in the diabetic animals was due to the destruction of the beta cells in pancreas $[28,29]$. The treatment of the CREE and UA combination showed best efficacy in Group 5, which was in equivalence to the activity of the standard drug in Group 6 (Table 2). It is assumed that it might be due to the stimulation of beta cell to secrete insulin or it may also be possible due to the regeneration of beta cells of pancreas. Our results corroborate the previously reported research studies of similar kind [30-32].

The synthesis of hepatic glycogen content is decreased due to diabetic condition, and it may be due to the low level of insulin in the body which inactivates glycogen synthase mechanism [33]. The decrease in glycogen synthesis has been reported in several previously reported research articles [34]. The restoration of hepatic glycogen content in Group 5 indicates that the combination of CREE and UA stimulates the glycogen synthase enzyme by boosting the insulin production from beta cells (Figure 2).

Antioxidant enzymes like SOD, CAT, GSH, and GPx play an important character in the prevention of damage caused by oxidative stress in the cells $[20,35,36]$. SOD scavenges upon the radical of superoxide and changes it into hydrogen peroxide. On the other hand, CAT reduces hydrogen peroxide into water molecule and hence protects the tissues from reactive hydroxyl radicals. GSH is also involved in the same process [37]. When the level of SOD is increased unproportionally to GPx increase, there is an overload of peroxide that builds up inside the cell [38]. In diabetic condition, elevated blood glucose can inactivate these antioxidant enzymes and hence an oxidative stress occurs which subsequently causes lipid peroxidation [39]. The activities of SOD, CAT, GSH, and GPx was elevated and restored to normal while that of the LPO was reduced to normalize; this led to the attenuation of oxidative stress (Figure 3 ).

\section{Conclusion}

The present study concludes that CREE and UA showed potent hypoglycemic activity in STZ-induced diabetes in Wistar strain rats when compared with the normal rats. This 


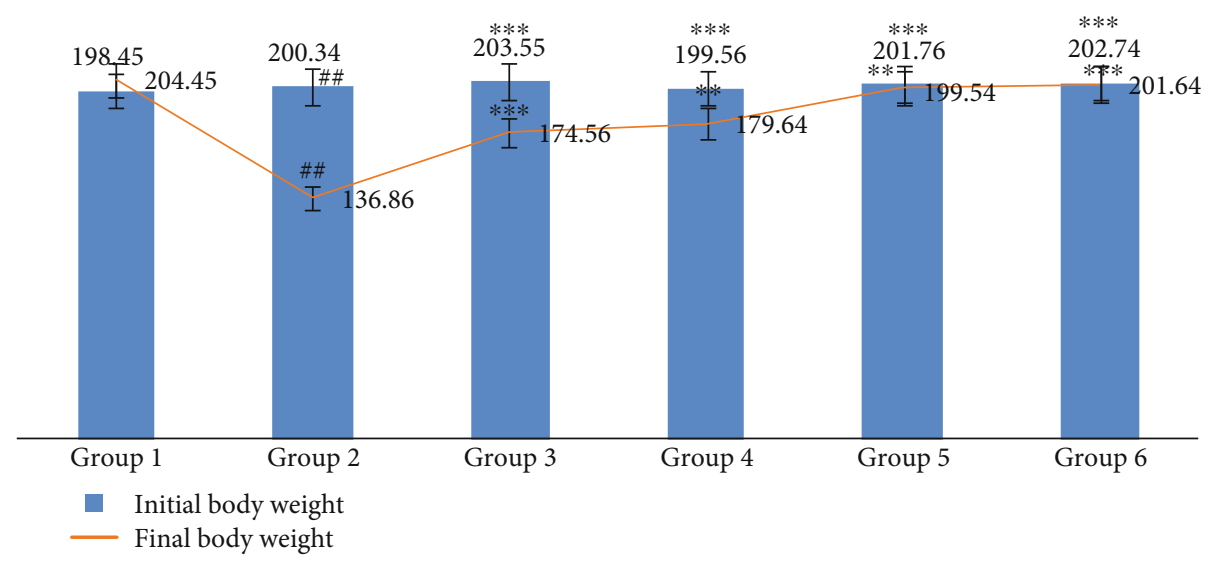

FIGURE 3: Effect Catharanthus roseus and ursolic acid and combination on antioxidant enzyme level. ${ }^{* *} P<0.01$ is considered significant; ${ }^{* * *} P<0.001$ is considered highly significant. Group 2 compared with Group 1 , and comparison is considered significant. ${ }^{\# \#} P<0.01$ is considered very significant; ${ }^{\# \#} P<0.001$ is considered highly significant.

combination treatment of CREE and UA is found and shown to enhance the efficacy and reduce the side effects. Significant improvement in body weight, levels of serum insulin, liver glycogen, and antioxidant enzymes activity were observed with best effect in the combined treatment group rather than the single drug treatment group. More detailed investigations are required to further strengthen these novel findings and further researches required in order to determine the specific mechanism of action of the antidiabetic effect.

\section{Data Availability}

We, the authors, support and endorse the FAIR Guiding Principles for scientific data management and stewardship-findability, accessibility, interoperability, and reusability. The experimental data used to support the findings of this study are included within the manuscript. However, additional information from this study may be obtained upon request to the corresponding author (aftab786sa@hotmail.com, or abdulsalam@kau.edu.sa). We ensured that Hindawi (Oxidative Medicine and Cellular Longevity) has the rights necessary for the proper administration of electronic rights and online dissemination of the manuscript entitled "Catharantus roseus combined with ursolic acid attenuates streptozotocin induced diabetes thourough insulin secretion and glycogen storage".

\section{Conflicts of Interest}

The authors declare no conflict of interest.

\section{Acknowledgments}

This project was funded by the Deanship of Scientific Research (DSR), King Abdulaziz University, Jeddah, under grant no. G-390-140-1440. The authors, therefore, acknowledge with thanks DSR technical and the financial support.

\section{References}

[1] N. H. Cho, J. E. Shaw, S. Karuranga et al., "IDF diabetes atlas: global estimates of diabetes prevalence for 2017 and projections for 2045," Diabetes Research and Clinical Practice, vol. 138, pp. 271-281, 2018.

[2] American Diabetes Association, "5. Lifestyle Management: Standards of Medical Care in Diabetes-2019," Diabetes Care, vol. 42, Supplement 1, pp. S46-S60, 2018.

[3] R. Heijden, D. Jacobs, W. Snoeijer, D. Hallard, and R. Verpoorte, "The Catharanthus alkaloids: pharmacognosy and biotechnology," Current Medicinal Chemistry, vol. 11, no. 5, pp. 607-628, 2004.

[4] Ł. Woźniak, S. Skąpska, and K. Marszałek, "Ursolic acid-a pentacyclic triterpenoid with a wide spectrum of pharmacological activities," Molecules, vol. 20, no. 11, pp. 2061420641, 2015.

[5] Y. Zhang, L. Huang, H. Shi et al., "Ursolic acid enhances the therapeutic effects of oxaliplatin in colorectal cancer by inhibition of drug resistance," Cancer Science, vol. 109, no. 1, pp. 94102, 2018.

[6] S. Shishodia, S. Majumdar, S. Banerjee, and B. B. Aggarwal, "Ursolic acid inhibits nuclear factor-kappaB activation induced by carcinogenic agents through suppression of IkappaBalpha kinase and p65 phosphorylation: correlation with down-regulation of cyclooxygenase 2, matrix metalloproteinase 9, and cyclin D1," Cancer Research, vol. 63, no. 15, pp. 4375-4383, 2003.

[7] J. Zou, J. Lin, C. Li et al., "Ursolic acid in cancer treatment and metastatic chemoprevention: from synthesized derivatives to nanoformulations in preclinical studies," Current Cancer Drug Targets, vol. 19, no. 4, pp. 245-256, 2019.

[8] X. Wang, F. Zhang, L. Yang et al., "Ursolic acid inhibits proliferation and induces apoptosis of cancer cells in vitro and in vivo," Journal of Biomedicine and Biotechnology, vol. 2011, Article ID 419343, 8 pages, 2011.

[9] B. Liu, Y. Liu, G. Yang, Z. Xu, and J. Chen, "Ursolic acid induces neural regeneration after sciatic nerve injury," Neural Regeneration Research, vol. 8, no. 27, pp. 2510-2519, 2013.

[10] N. Kaewthawee and S. Brimson, "The effects of ursolic acid on cytokine production via the MAPK pathways in leukemic Tcells," EXCLI Journal, vol. 12, pp. 102-114, 2013. 
[11] S. C. Gnoatto, A. Dassonville-Klimpt, S. Da Nascimento et al., "Evaluation of ursolic acid isolated from Ilex paraguariensis and derivatives on aromatase inhibition," European Journal of Medicinal Chemistry, vol. 43, no. 9, pp. 1865-1877, 2008.

[12] J. Liobikas, D. Majiene, S. Trumbeckaite et al., "Uncoupling and antioxidant effects of ursolic acid in isolated rat heart mitochondria," Journal of Natural Products, vol. 74, no. 7, pp. 1640-1644, 2011.

[13] S. D. Kunkel, C. J. Elmore, K. S. Bongers et al., "Ursolic acid increases skeletal muscle and brown fat and decreases dietinduced obesity, glucose intolerance and fatty liver disease," PLoS One, vol. 7, no. 6, article e39332, 2012.

[14] A. Ahmad, M. F. Abuzinadah, H. M. Alkreathy, B. Banaganapalli, and M. Mujeeb, "Ursolic acid rich Ocimum sanctum L leaf extract loaded nanostructured lipid carriers ameliorate adjuvant induced arthritis in rats by inhibition of COX-1, COX-2, TNF- $\alpha$ and IL-1: pharmacological and docking studies," PLoS One, vol. 13, no. 3, article e0193451, 2018.

[15] X. Y. Jin, H. Chen, D. D. Li, A. L. Li, W. Y. Wang, and W. Gu, "Design, synthesis, and anticancer evaluation of novel quinoline derivatives of ursolic acid with hydrazide, oxadiazole, and thiadiazole moieties as potent MEK inhibitors," Journal of Enzyme Inhibition and Medicinal Chemistry, vol. 34, no. 1, pp. 955-972, 2019.

[16] W. M. Al-Shaqha, M. Khan, N. Salam, A. Azzi, and A. A. Chaudhary, "Anti-diabetic potential of Catharanthus roseus Linn. and its effect on the glucose transport gene (GLUT-2 and GLUT-4) in streptozotocin induced diabetic wistar rats," BMC Complementary and Alternative Medicine, vol. 15, no. 1, 2015.

[17] M. G. Ajuru, G. Ajuru, F. W. Nmom, C. W. Worlu, and P. G. Igoma, "Acute toxicity study and determination of median lethal dose of Catharanthus roseus in Wistar Albino rats," Journal of Applied Sciences, vol. 19, no. 3, pp. 217-222, 2019.

[18] K. S. Balamash, H. M. Alkreathy, E. H. Al Gahdali, S. O. Khoja, and A. Ahmad, "Comparative biochemical and histopathological studies on the efficacy of metformin and virgin olive oil against streptozotocin-induced diabetes in Sprague-Dawley rats," Journal Diabetes Research, vol. 2018, p. 4692197, 2018.

[19] A. Ahmad and H. M. Alkreathy, "Comparative biochemical and histopathological studies on the efficacy of metformin and Nigella sativa oil against thioacetamide-induced acute hepatorenal damage in rats," Biomedical Research, vol. 29, no. 15, pp. 3106-3116, 2018.

[20] N. Shivavedi, M. Kumar, G. N. V. C. Tej, and P. K. Nayak, "Metformin and ascorbic acid combination therapy ameliorates type 2 diabetes mellitus and comorbid depression in rats," Brain Research, vol. 1674, pp. 1-9, 2017.

[21] S. Mortensen, D. Bernal-Franco, L. F. Cole, S. Sathitloetsakun, E. J. Cram, and C. W. T. Lee-Parsons, "EASI transformation: an efficient transient expression method for analyzing gene function in Catharanthus roseus seedlings," Frontiers in Plant Science, vol. 10, p. 755, 2019.

[22] K. Akahane, T. Inoue, A. Yokoyama et al., "Efficacy of mitiglinide combined with dapagliflozin in streptozotocinnicotinamide-induced type 2 diabetic rats and in Zucker fatty rats," Drug Research, vol. 65, no. 8, pp. 416-421, 2015.

[23] F. Zhong and Y. Jiang, "Endogenous Pancreatic $\beta$ Cell Regeneration: A Potential Strategy for the Recovery of $\beta$ Cell Deficiency in Diabetes," Frontiers in Endocrinology, vol. 10, p. 101, 2019.
[24] A. Arya, S. C. Cheah, C. Y. Looi, H. Taha, M. R. Mustafa, and M. A. Mohd, "The methanolic fraction of Centratherum anthelminticum seed downregulates pro-inflammatory cytokines, oxidative stress, and hyperglycemia in STZnicotinamide induced type 2 diabetic rats," Food and Chemical Toxicology, vol. 50, no. 11, pp. 4209-4220, 2012.

[25] A. Tahara, A. Matsuyama-Yokono, and M. Shibasaki, "Effects of antidiabetic drugs in high-fat diet and streptozotocinnicotinamide-induced type 2 diabetic mice," European Journal of Pharmacology, vol. 655, no. 1-3, pp. 108-116, 2011.

[26] Y. Wang-Fischer and T. Garyantes, "Improving the reliability and utility of streptozotocin-induced rat diabetic model," Journal Diabetes Research, vol. 2018, p. 8054073, 2018.

[27] R. B. Kasetti, M. D. Rajasekhar, V. K. Kondeti et al., “Antihyperglycemic and antihyperlipidemic activities of methanol: water (4:1) fraction isolated from aqueous extract of Syzygium alternifolium seeds in streptozotocin induced diabetic rats," Food and Chemical Toxicology, vol. 48, no. 4, pp. 1078-1084, 2010.

[28] S. Kurup and R. R. Bhonde, "Combined effect of nicotinamide and streptozotocin on diabetic status in partially pancreatectomized adult BALB/c mice," Hormone and Metabolic Research, vol. 32, no. 8, pp. 330-334, 2000.

[29] R. Chandran, T. Parimelazhagan, S. Shanmugam, and S. Thankarajan, "Antidiabetic activity of Syzygium calophyllifolium in streptozotocin-nicotinamide induced type-2 diabetic rats," Biomedicine and Pharmacotherapy, vol. 82, pp. 547-554, 2016.

[30] J. Eliza, P. Daisy, S. Ignacimuthu, and V. Duraipandiyan, "Antidiabetic and antilipidemic effect of eremanthin from Costus speciosus (Koen.)Sm., in STZ-induced diabetic rats," Chemico-Biological Interactions, vol. 182, no. 1, pp. 67-72, 2009.

[31] D. B. Asante, E. Effah-Yeboah, P. Barnes et al., "Antidiabetic effect of young and old ethanolic leaf extracts of Vernonia amygdalina: a comparative study," Journal Diabetes Research, vol. 2016, p. 8252741, 2016.

[32] C. Z. Wu, S. H. Ou, L. C. Chang, Y. F. Lin, D. Pei, and J. S. Chen, "Deficiency of Urokinase plasminogen activator may impair $\beta$ cells regeneration and insulin secretion in type 2 diabetes mellitus," Molecules, vol. 24, no. 23, p. 4208, 2019.

[33] M. A. Sullivan and J. M. Forbes, "Glucose and glycogen in the diabetic kidney: heroes or villains?,” eBioMedicine, vol. 47, pp. 590-597, 2019.

[34] L. Rossetti and A. Giaccari, "Relative contribution of glycogen synthesis and glycolysis to insulin-mediated glucose uptake. A dose-response euglycemic clamp study in normal and diabetic rats," Journal of Clinical Investigation, vol. 85, no. 6, pp. 17851792, 1990.

[35] F. A. Matough, S. B. Budin, Z. A. Hamid, N. Alwahaibi, and J. Mohamed, "The role of oxidative stress and antioxidants in diabetic complications," Sultan Qaboos University Medical Journal, vol. 12, no. 1, pp. 5-18, 2012.

[36] R. Vona, L. Gambardella, C. Cittadini, E. Straface, and D. Pietraforte, "Biomarkers of oxidative stress in metabolic syndrome and associated diseases," Oxidative Medicine and Cellular Longevity, vol. 2019, Article ID 8267234, 19 pages, 2019.

[37] J. Eliza, P. Daisy, and S. Ignacimuthu, "Antioxidant activity of costunolide and eremanthin isolated from Costus speciosus (Koen ex. Retz) Sm.," Chemico-Biological Interactions, vol. 188, no. 3, pp. 467-472, 2010. 
[38] I. Marrocco, F. Altieri, and I. Peluso, "Measurement and clinical significance of biomarkers of oxidative stress in humans," Oxidative Medicine and Cellular Longevity, vol. 2017, Article ID 6501046, 32 pages, 2017.

[39] O. M. Cecilia, C. G. José Alberto, N. P. José et al., “Oxidative stress as the main target in diabetic retinopathy pathophysiology," Journal Diabetes Research, vol. 2019, pp. 85624088562421, 2019. 